\title{
EXPECTATIVAS DA MÍDIA SOBRE O LEGADO DAS OLIMPÍADAS DE 2016:
}

\section{RACIONALIDADE INSTRUMENTAL E SUBSTANTIVA}

\section{DR. CARLOS ALBERTO FIGUEIREDO DA SILVA}

Professor Titular do Curso de Mestrado em Ciências da Atividade Física da Universidade

Salgado de Oliveira, Pró-reitor de Ensino do Centro Universitário Augusto Motta,

Pós-doutorado na Universidade do Porto (Porto - Portugal), Doutorado na Universidade Gama Filho

(Rio de Janeiro - Rio de Janeiro - Brasil)

E-mail: ca.figueiredo@yahoo.com.br

\section{DR ${ }^{\mathrm{a}}$. RENATA OSBORNE}

Professora Titular do Curso de Mestrado em Ciências da Atividade Física da Universidade Salgado de Oliveira (Niterói - Rio de Janeiro - Brasil), Doutorado na Florida Atlantic University

(Boca Raton - Flórida - USA)

E-mail: renataoc@oi.com.br

DR. MAURICIO MURAD

Professor Titular do Curso de Mestrado em Ciências da Atividade Física da Universidade Salgado de Oliveira (Niterói - Rio de Janeiro - Brasil), Doutorado na Universidade do Porto (Porto - Portugal)

E-mail:m.mauriciomurad@gmail.com

\section{DR. ROBERTO FERREIRA DOS SANTOS}

Professor Titular do Curso de Mestrado em Ciências da Atividade Física da Universidade Salgado de Oliveira (Niterói - Rio de Janeiro - Brasil), Doutorado na Universidade do Porto (Porto - Portugal)

E-mail: rob.fersantos@oi.com.br

\section{MS. RAFAEL CARVALHO DA SILVA MOCARZEL}

Mestrado em Ciências da Atividade Física na Universidade Salgado de Oliveira

(Niterói - Rio de Janeiro - Brasil)

E-mail: rafaelmocarzel@globo.com

\section{MS. MARCELO FARIA PORRETI}

Mestrado em Ciências da Atividade Física na Universidade Salgado de Oliveira

(Niterói - Rio de Janeiro - Brasil)

E-mail:marcelo-porretti@oi.com.br

\section{MS. RONALDO DOS SANTOS FIGUEIREDO}

Mestrado em Ciências da Atividade Física da Universidade Salgado de Oliveira

(Niterói - Rio de Janeiro - Brasil)

E-mail: rfigueiredo@oi.com.br

\section{MS. ELIANE GLÓRIA REIS DA SILVA SOUZA}

Mestrado em Ciências da Atividade Física da Universidade Salgado de Oliveira

(Niterói - Rio de Janeiro - Brasil)

E-mail: elianereis2002@hotmail.com 


\title{
MS. ORESTES MANOEL DA SILVA
}

Mestrado em Ciências da Atividade Física da Universidade Salgado de Oliveira (Niterói - RJ - Brasil), professor da Universidade Federal do Rio de Janeiro (UFRJ)

(Rio de Janeiro - Rio de Janeiro - Brasil)

E-mail:m.orestes@globo.com

\author{
MS. JOÃO DOMINGOS BEZERRA MANDARINO \\ Mestrado em Ciências da Atividade Física da Universidade Salgado de Oliveira, Professor \\ do Curso de Educação Física do Centro Universitário Augusto Motta \\ (Rio de Janeiro - Rio de Janeiro - Brasil) \\ E-mail: joaodbm@hotmail.com
}

\begin{abstract}
RESUMO
Este estudo tem por objetivo discutir a expectativa da mídia sobre o futuro legado dos Jogos Olímpicos de 2016, para a cidade do Rio de Janeiro. Foram consultadas 360 edições de cinco dos principais jornais editados no estado do Rio de Janeiro. Dezessete categorias foram construídas, a partir da análise das notícias veiculadas nos tablóides. O enfoque utilizado na discussão aproveita as concepções de racionalidade instrumental e substantiva para analisar os limites históricos que a razão instrumental nos impõe e também a incessante tentativa de ultrapassá-los e de superá-los.
\end{abstract}

PALAVRAS-CHAVE: Jogos Olímpicos; megaeventos; racionalidade substantiva; legado.

\section{INTRODUÇÃO}

O que comumente chama-se modernidade e principalmente pós-modernidade tem na idéia de desenvolvimento um dos núcleos conceituais das representações coletivas em relação às diferentes visões de mundo, isto é, as ideologias. O termo desenvolvimento, não raro confundido com a noção de crescimento, representa um imaginário que remete à expansão tecnológica, "progresso" e, num certo sentido, a uma visão positiva - denotando uma perspectiva otimista.

Entretanto, a noção de desenvolvimento, na maioria das vezes, está pautada num reducionismo que se restringe a aspectos econômicos e técnicos, meramente quantitativos. $O$ incremento da técnica se faz, em muitos casos, à custa da criação e da importância de valores substantivos. Para Furtado (2000, p. 8), "Na civilização industrial, o gênio inventivo do homem foi canalizado de preferência para a criação da técnica, o que explica sua extraordinária capacidade expansiva". Este autor afirma que o poder de difusão da técnica é muito maior do que o poder de difusão dos valores. Assim, a racionalidade instrumental tem prevalecido em relação à racionalidade substantiva. A racionalidade instrumental volta-se quase que exclusivamente para o 
mercado e, portanto, para uma lógica social de tipo capitalista, enquanto a racionalidade substantiva busca os ditos projetos de país, de cidadania, de nacionalidade.

A racionalidade substantiva trata do intangível, do mérito intrínseco, dos valores, envolvendo ética e estética; em síntese: os valores humanos. Já a racionalidade instrumental focaliza o tangível, a técnica, envolvendo a relação custo/benefício, numa visão fundamentada no pragmatismo.

A sociedade industrial, capitalista, com o predomínio da economia sobre outras áreas do conhecimento, gerou um modelo de "desenvolvimento" de tipo predatório, mais quantitativo e concentrador de riquezas, poder e oportunidades. Boff (1994, p. 21) adverte que o desenvolvimento econômico não pode ser "um fim em si mesmo", mas que "agora importa colocar a economia a serviço do desenvolvimento social, a economia política a serviço do bem estar da sociedade e da natureza". A crise ambiental que vivemos atualmente e que põe em risco a sobrevivência da espécie e do planeta é uma questão ética, de valores e de necessidade de limites à ação antropocêntrica (COSTA, 2006).

Em resposta a esse tipo de desenvolvimento predatório, surgiram termos tais como sustentabilidade e desenvolvimento sustentável. Freitas (2004, p. 548) explica que o desenvolvimento sustentável é formalmente explicitado em 1986, no Relatório Brundtland, o Nosso Futuro Comum, como: "o desenvolvimento que satisfaz as necessidades do presente sem comprometer a possibilidade das gerações futuras satisfazerem as suas próprias necessidades".

Temos como argumentos, neste trabalho, observar não apenas os meios, mas também os fins, buscando estimular a discussão sobre os possíveis legados de megaeventos esportivos, como ferramentas do empreendedorismo, da melhoria da qualidade de vida e do desenvolvimento sustentável.

Para isso, elegemos como pergunta norteadora: qual é a expectativa da mídia sobre o futuro legado dos Jogos Olímpicos de 2016, observando-se as perspectivas de racionalidades substantiva e instrumental?

\section{RACIONALIDADE INSTRUMENTAL E SUBSTANTIVA}

A característica distintiva, fundamental e específica da sociedade ocidental, burguesa e capitalista é a racionalização (WEBER, 200 I). A razão, que é a faculdade subjetiva do pensar, mas do pensar com a lógica pragmática, instrumental, com a logicidade do mercado, enfim, se instalou em todas as dimensões e se personificou nos objetos (BAUDRILLARD, 2009). A razão tornou-se uma mercadoria. É o fetiche da mercadoria preconizado por Karl Marx (1959), em sua obra maior, O Capital. Segundo a visão marxista da sociedade burguesa e de seu modo de produção, tudo 
resulta por transformar-se em mercadoria, visando à reprodução de seus elementos mais imediatos: o lucro e a renovação tecnológica.

A busca pela eficiência e eficácia fez a razão tornar-se racionalidade, isto é, transformar-se numa dimensão da vida em sociedade e de suas instituições sociais. Em toda ação humana, observa-se a relação entre meios e fins. De acordo com Freitag (1994, p. 90), Weber postula "como racional toda a ação que se baseia no cálculo, na adequação de meios e fins, procurando obter com um mínimo de dispêndios um máximo de efeitos desejados, evitando-se ou minimizando-se todos os efeitos colaterais indesejados".

A essa racionalidade, que se desenvolveu com a evolução da técnica e do método científico no ocidente, chama-se de instrumental. A ela atrelam-se as idéias de ordem, unidade, eficácia, resultado, performance, sistema, objetividade etc. Em resumo, pode ser vinculada a qualquer organização, evento coletivo ou a seus resultados, como indicou o eminente sociólogo brasileiro Guerreiro Ramos, ao estudar de forma pioneira em nossa sociologia esses fatores estruturantes, que nivelam tanto as corporações públicas às privadas. De acordo com o autor, na atualidade prevalece a racionalidade instrumental, efeito de uma sociedade baseada no capital e de seus modelos de vida centrados no mercado, esta "entidade" hegemônica das formações da modernidade e da pós-modernidade (RAMOS, | 98 I).

Entretanto, outra racionalidade convive com o sistema da unidade. A esta nos referiremos como substantiva. Muitas instituições, empresas, organizações não governamentais (ONGs), têm-na como referência. De acordo com Serva (1993, p. 37):

As organizações substantivas parecem brotar pela força espontânea de milhares de indivíduos, espalhados por todo mundo, que se têm reunido em torno de ideais e princípios determinantes de ações conjuntas as quais, por sua vez, acabam configurando práticas sócio-organizacionais relativamente descompromissadas com o estatuto essencialmente sistêmico da sociedade burocratizada.

Nessas organizações, percebe-se que o pensamento não é transformado em um instrumento; "existe uma preocupação com o efetivo resgate da condição humana. Autenticidade, dignidade, respeito à individualidade, solidariedade, afetividade, são alguns dos aspectos marcantes" (SERVA, 1993, p. 4I).

A perspectiva do desenvolvimento substantivo abarcou já no final do século XX a ideia de sustentabilidade e ética planetária (BOFF, 1994) envolvendo os valores, as crenças, os conceitos, os conteúdos, os projetos e não apenas o desenvolvimento da técnica, da produção e da reprodução do capital. Um bom complemento para a reflexão do conceito de racionalidade substantiva pode ser encontrado na teoria da ação comunicativa de Habermas ( 1989 ). Isto, porque permite fundamentar uma 
visão mais holística e em consequência resgata a dinâmica do método dialético, enquanto alternativa à atomização, ao isolamento, à fragmentação, ao imediatismo, ao pragmatismo.

Habermas e outros representantes da escola de Frankfurt desenvolveram uma crítica por vezes radical às lógicas dominantes na sociedade industrial e à sua racionalidade instrumental. Habermas reconhece o lugar da racionalidade instrumental e até mesmo a sua importância, mas não aceita a sua universalização - A técnica e a ideologia como ciência (HABERMAS, 1973) - preconizando que em outras esferas da vida devem imperar outro tipo de racionalidade: a racionalidade substantiva. Aqui operam outros fatores, como a ação comunicativa entre os segmentos sociais e a transdisciplinaridade dos conceitos, dos conhecimentos, das práticas, dos projetos humanos e dos eventos sócio-culturais.

“Max Weber introduziu a concepção de 'racionalidade' como característica da forma capitalista de atividade econômica, da forma burguesa de trocas no nível do direito privado e da forma burocrática de dominação" (HABERMAS, 1973, p. 3). Weber ao investigar esse tipo de sociedade desencantada, basicamente em um de seus livros seminais, Economia e sociedade, publicação póstuma datada de 1922 (começou a escrevê-lo em 1909), apresenta uma tipologia da dominação (herrschaft), com seus correspondentes níveis de racionalidade (WEBER, 1978). Este importante capítulo de sua obra chamou a atenção de pensadores que se seguiram a ele, como Habermas, que agregou contribuições significativas às questões colocadas pioneiramente.

A racionalidade substantiva se expressa pelos valores intrínsecos que a inspiram, tendo por base uma consistente substância (conteúdo) ética. Além disto, a racionalidade substantiva deve ser direcionada por critérios de natureza mais universal e transcendente. Aqui, segundo os estudiosos de Habermas, podemos situar seu maior mérito e seu ponto discutível na condição de teórico e pensador. A tentativa de universalização é um ponto positivo, no conjunto de seu trabalho, na medida em que se opõe à fragmentação e atomização da modernidade e mais ainda da pós-modernidade. Por outro lado, uma crítica possível é a de que a totalização excessiva pode não dar conta das especificidades locais, particulares e concretas, que no fundo são as causas na investigação científica. Uma estrutura muito universal e transcendente pode tornar-se por demais abstrata.

De outro modo, a racionalidade instrumental diz respeito aos níveis de aperfeiçoamento e apuro técnico-científico com os quais se podem alcançar os fins, os resultados pretendidos. Desta forma, está fundamentada na quantificação, na calculabilidade e na instrumentalização (aspectos que Weber anteviu) da relação custo-benefício, que é típica do mercado e da competitividade utilitarista. 


\section{MEGAEVENTOS ESPORTIVOS E SUSTENTABILIDADE}

Embora o termo desenvolvimento sustentável esteja amplamente difundido, o seu significado provoca controvérsia e desentendimentos (LANDORF; DOSCHER; ROCCO, 2008). Alguns autores discordam do termo desenvolvimento ligado à palavra sustentável; consideram que esses termos não são compatíveis, resultando no predomínio de uma economia pragmática e imediatista, onde o lucro é o mais importante. Lima (2009) se vale da expressão sociedades sustentáveis como alternativa. Mas o entendimento e a aplicação do desenvolvimento sustentável é uma questão complexa; e nesse sentido concordamos com Lima (2003, p. 105- I06):

[...] a definição de desenvolvimento sustentável veiculada pelo Relatório Brundtland permite uma pluralidade de leituras que oscilam, desde um sentido avançado de desenvolvimento, associado à justiça socioambiental e renovação ética, até uma perspectiva conservadora de crescimento econômico ao qual se acrescentou uma variável ecológica. Esta polissemia revela o curioso paradoxo de reunir, ao mesmo tempo, a força e a fraqueza do discurso, a depender do olhar e dos interesses de quem observa.

A sustentabilidade traz em seu bojo o desenvolvimento inteligente, preocupado com três componentes-chave: sociedade, ambiente e economia (UNESCO, 2005). Portanto, como proposta de comprometimento sociocultural, propõe uma nova ética global, minimizando as desigualdades sociais, a pobreza, cuidando da vida humana e dos demais seres vivos. É a noção de globalização contra hegemônica, defendida pelo sociólogo português Boaventura de Souza Santos (apud MURAD, 2007). Busca, portanto, preservar os recursos renováveis e não-renováveis, estimulando as novas e futuras gerações a enfrentar a dominação e exploração humana de maneira crítica, reflexiva, atitudinal e procedimental (COSTA, 2006).

$O$ início do século $X X I$ tem apresentado uma multiplicidade de discursos, muitos deles denotam perspectivas negativistas sobre cidades e desenvolvimento. O foco recai na decadência, violência, insegurança, poluição, degradação ambiental, caos nos transportes etc. Outras formações discursivas têm se mostrado mais otimistas. É o caso dos discursos ligados aos megaeventos no campo do esporte, incluem-se, neste âmbito, os discursos sobre legado dos Jogos Olímpicos para as cidades sede.

Acserald (2005, p. II) afirma que o urbano ganhou um novo cenário de enunciação: "ante o que alguns entendem por crise identitária das cidades, são acionadas 'tecnologias do espírito' voltadas para uma recomposição das subjetividades urbanas".

Costa (2006, p. 56) cita que "nas grandes cidades, o meio ambiente se tornou extremamente complexo e complicado, e cabe ao ser humano recriar esse espaço 
de forma a mantê-lo propício à sua própria humanização". De forma harmoniosa, a convivência entre esporte e ambiente ocorre em diversas modalidades. Procuram-se meios de se desenvolver mecanismos em que os participantes se sintam parte do ambiente e desta forma protegendo-o e preservando-o.

Entretanto, a meta narrativa utópica que, por vezes, está presente nos discursos otimistas vinculados ao esporte, deixa transparecer que a sinalização da cidade para o mundo tem por objetivo a construção de sua identidade. $\bigcirc$ argumento da identidade sustenta-se na concepção de reconstrução, que serve, então, como instrumento dos operadores políticos para resgatar a cidade "não mais como circunscrita a seu tempo presente, mas como referente a um passado de glória e a um futuro radioso" (ACSELRAD, 2005, p. 12). Essa concepção necessita de que a cidade seja aprovada pelas forças de mercado, passando a ser controlada e vigiada. Com efeito, neutraliza-se a política e a segurança passa a ser base estruturante para todas as ações estatais (COMPANS, 2005).

Para Bauman (2005), não se pode falar de identidade e sim de identidades; estas flutuam no ar, são múltiplas, multifacetadas e por vezes até contraditórias. Há de se fazer a distinção entre identidades (mais permanentes, estruturais e estruturantes) e identificações (passageiras, voláteis e conjunturais). Algumas dessas identidades são de nossa própria escolha, mas outras são "infladas e lançadas pelas pessoas em nossa volta" (p. 19). É necessário, para ele, que estejamos em alerta para defendermos aquelas que escolhemos em relação às outras que nos são impostas.

Em 2009, o Rio de Janeiro foi escolhido como cidade sede para os Jogos Olímpicos de 20 16. No mesmo ano, foi eleita como "a cidade mais feliz do mundo" pela revista Forbes (GREENBURG, 2009), a partir de uma pesquisa de mercado do instituto GfK Custom Research North America, em que foram ouvidas dez mil pessoas em mais de vinte países. De acordo com o estudo, o bom humor, o estilo de vida e o carnaval, foram os atributos mais citados. A pesquisa revelou aspectos intangíveis da cidade, que a caracterizaram dentre tantas outras.

Podemos assumir esses atributos como escolhidos pelos cariocas, pelos brasileiros? De certo, eles ocultam a realidade vivida no cotidiano do Rio de Janeiro. Entretanto, todo o brilho da cidade foi utilizado para que o Comitê Olímpico Internacional (COI) a escolhesse como sede. Não obstante, os atributos de ser uma cidade violenta, desigual, suja, caótica, são também identidades da cidade do Rio de Janeiro. De fato, esses atributos identitários não são uma exclusividade dela e sim de várias metrópoles do mundo.

O dado que chama a atenção é que bom humor, estilo de vida e carnaval estão mais relacionados ao substantivo do que ao instrumental. No entanto, os aspectos econômicos e ambientais estão relacionados à sociedade carioca quando 
se apresentam esses atributos. As coisas estão unidas e ao mesmo tempo separadas. É dessa relação entre a racionalidade instrumental e a racionalidade substantiva que se constroem as identidades.

\section{EXPECTATIVA DA MÍDIA EM RELAÇÃO AO LEGADO DE 2016}

Antes e após a eleição do Rio de Janeiro como sede dos Jogos Olímpicos de 2016, a mídia iniciou um processo de discussão sobre o legado do evento para a cidade. Entre o dia $1^{\circ}$ de outubro de 2009 e o dia 31 de dezembro de 2009, a equipe que desenvolveu este estudo catalogou as notícias que abordaram o tema do legado dos Jogos para a cidade do Rio de Janeiro. Foram pesquisados os jornais $\bigcirc$ Globo, O Dia, O Fluminense, Jornal do Brasil e Lance. Num total de 360 edições. O levantamento das expectativas da mídia foi realizado nas edições impressas e também online.

Foram construídas 17 categorias a partir das análises das notícias, que seguiram as orientações de Bardin (1977), explicitadas em Silva e Devide (2009), a saber:

।. Exclusão mútua - uma expectativa não poderia ser suscetível de compor mais de uma categoria;

2. Homogeneidade - as categorias foram construídas de forma a não permitir que expectativas com significados diferentes pudessem fazer parte da mesma categoria;

3. Pertinência - as categorias foram criadas após a classificação analógica das expectativas, de modo que estivessem adaptadas aos dados;

4. Objetividade e fidelidade - de forma a se evitar que uma expectativa pudesse ser categorizada de diferentes maneiras, estabelecendo o critério de confronto e de entrada na categoria.

Inicialmente, a expectativa era inserida em determinada categoria, de acordo com o seu campo semântico; em seguida, era enquadrada em outras categorias até que restasse uma única opção.

Faria Júnior (1980) considera como noção de validade a capacidade que um sistema de categorias tem para classificar todos os eventos que se proponha a estudar. No estudo da exaustividade (como noção de validade) consideraram-se como universo: todas as notícias, manchetes, fotos, artigos de fundo e crônicas especializadas publicadas nos jornais $\bigcirc$ Globo, Jornal do Brasil, $\bigcirc$ Dia, $\bigcirc$ Fluminense e Lance, que expressaram argumentações sobre o evento em foco.

Um sistema de categorias é considerado válido, pela dimensão da exaustividade, quando ele consegue identificar o conteúdo estabelecido no objeto de estudo da pesquisa. Pensamos ser importante mencionar que o sistema de categorias 
foi construído a posteriori como sugere Vala (1986). Essa forma de estabelecer as categorias é sugerida para as pesquisas que envolvem meios de comunicação em geral (VALA, 1986, p. I13).

Realizado o trabalho de categorização, encontramos os seguintes resultados demonstrados no Quadro I.

\begin{tabular}{ll} 
Quadro I - Distribuição das categorias de expectativas da mídia por percentual \\
\cline { 2 - 2 } CATEGORIAS & $\%$ \\
\hline Transporte & $25 \%$ \\
Empregos & $15 \%$ \\
Meio ambiente & $8 \%$ \\
Vias públicas & $8 \%$ \\
Turismo & $7 \%$ \\
Segurança pública & $7 \%$ \\
Sinalização da cidade & $5 \%$ \\
Negócios & $5 \%$ \\
Saúde & $3 \%$ \\
Transparência política & $3 \%$ \\
Saneamento público & $3 \%$ \\
Reassentamento de famílias & $3 \%$ \\
Internet banda larga & $2 \%$ \\
Segurança privada & $2 \%$ \\
Construção Civil & $2 \%$ \\
Reciclagem do lixo & $2 \%$ \\
Restauração da cidade & $2 \%$ \\
\hline
\end{tabular}

Ao observarmos o mapa das categorias (Figura I), percebe-se que a maior área compreende as categorias Transporte (25\%), Empregos (I5\%), Meio Ambiente e Vias Públicas (ambas com 8\%), Turismo e Segurança Pública (ambos com 7\%), Sinalização da Cidade e Negócios (ambos com 5\%). 


\section{Mapa percentual}

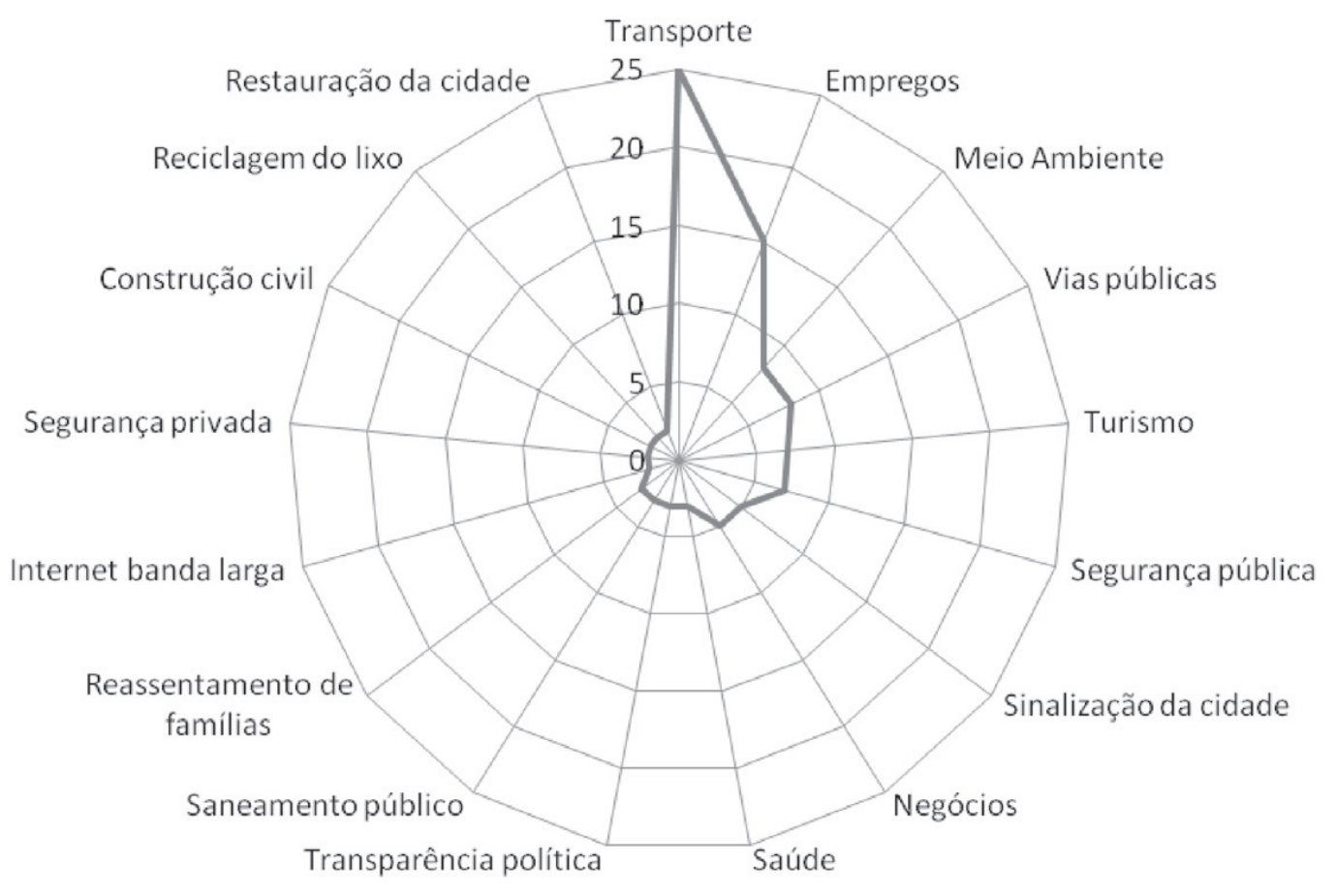

Figura I: Mapa das categorias de expectativas da mídia por percentual.

A categoria com o maior percentual foi Transporte, com 25\% das notícias veiculadas. A expectativa da mídia em relação ao legado dos Jogos Olímpicos de 2016 focaliza o Bus Rapid Transit (BRT). Esta via rápida para os ônibus tem recebido atenção especial por parte da mídia. Espera-se que esse sistema acabe com a sobreposição de linhas e efetive o reordenamento e integração dos transportes coletivos da cidade a partir da criação de corredores exclusivos. Essa ideia é inspirada no modelo da cidade de Curitiba'. Assim, a prioridade deixaria de ser o transporte individual para ser o transporte coletivo.

A mudança, que vai acabar com a sobreposição de linhas, prevê o reordenamento e integração dos transportes coletivos da cidade a partir da criação de corredores exclusivos, o famoso BRT (Bus Rapid Transit), mudando a prioridade do transporte individual para o coletivo (BALLOCO, 2009, p. I).

Além do BRT, a mídia impressa também destacou, nesta categoria: a reforma do aeroporto internacional, trens e ferrovias, linhas de metrô e introdução de ciclovias.

I. Cidade brasileira situada na região Sul do país, reconhecida por seu mérito em questões organizacionais, educacionais e culturais. 
Em segundo lugar, surge a categoria Empregos, com I 5\% das notícias veiculadas. Espera-se que novos postos de trabalho permanentes surjam com a realização da olimpíada. No setor de hotéis, bares e restaurantes, a expectativa durante a realização do evento é de pelo menos vinte mil novas vagas.

A realização de uma olimpíada estimula vários setores da economia, sobretudo construção civil e serviços. A diretora de Desenvolvimento Econômico da Federação das Indústrias do Rio (Firjan), Luciana de Sá, cita um estudo do Instituto municipal de Urbanismo Pereira Passos (IPP), ao afirmar que os benefícios seriam duradouros: - Pelo menos I 5 mil novos postos de trabalhos permanentes podem ser criados apenas por conta dos jogos. "O efeito multiplicador no Rio desses investimentos pode se dar de uma forma até mais permanente do que em outras cidades porque, antes das Olimpíadas, haverá aqui outros eventos". 0 presidente do Sindicato dos Hotéis, Bares e Restaurantes, Alexandre Sampaio, cita uma pesquisa feita pelo Departamento Intersindical de Estatística e Estudos Socioeconômicos (Dieese), que estima a abertura de pelo menos 20 mil novas vagas em setores como hospedagem, gastronomia, entretenimento e serviços turísticos em todo o país nos próximos anos (MAGALHÃES, 2009, p. I).

Em terceiro lugar aparecem as categorias Meio Ambiente (8\%) e Vias Públicas (8\%). Em relação ao meio ambiente, as notícias focalizam a contenção da degradação ambiental do complexo de lagoas e da baía de Guanabara. Espera-se que haja dragagem e recuperação das margens dos canais, implantação de unidades de tratamento de água, aumento da rede de esgoto e implantação de programas de educação ambiental. Em relação às vias públicas, a expectativa da mídia concentrase na construção de mergulhões na autoestrada Lagoa-Barra, no alargamento das avenidas, na introdução de ciclovias e na construção de novos túneis.

Em quarto lugar aparecem as categorias Turismo (7\%) e Segurança Pública (7\%). Espera-se um grande aquecimento na área de turismo. Entretanto, existe a preocupação com o transporte, principalmente, aeroportos e portos, que são algumas das áreas que precisam de pesados investimentos.

O Rio e o Brasil precisam muito aprimorar a cultura de receber. Treinamento, as empresas podem fazer. Mas não adianta treinar pessoas, achar que vamos construir mais hotéis, se a infraestrutura de aeroportos e portos não estiver pronta para atender à demanda - afirmou Werneck (RIBEIRO, 2009, p. I).

No que concerne à segurança pública, a expectativa é no aumento do investimento financeiro, no aparelhamento das equipes, no treinamento dos policiais e na implantação de Unidade de Polícia Pacificadora (UPPs). Em notícia veiculada no Jornal $\bigcirc$ Fluminense, o então ministro da justiça Tarso Genro faz algumas considerações: 
"Vamos ver agora a forma jurídica necessária para que esse ritmo de implantação das UPPs seja acelerado e tenhamos um avanço positivo na segurança pública no estado não somente em relação à preparação para as Olimpíadas. Constatamos que, se o ritmo atual de investimentos e de qualificação da segurança pública do Estado do Rio continuasse como está não chegaríamos a 2016 numa situação satisfatória. Portanto, teremos de triplicar o ritmo dos trabalhos e dos investimentos para que a segurança melhore e estejamos preparados em 2016", afirmou o ministro (RECURSOS, 2009).

Em seguida aparecem as categorias Sinalização da Cidade (5\%) e Negócios (5\%). A categoria negócios não se confunde com turismo, visto que, o tratamento dado pela mídia ao turismo se descolava de outras categorias. Negócios envolvem o surgimento de novos empreendimentos na cidade, com a criação de estruturas organizacionais ainda não existentes. A categoria Sinalização da Cidade demonstra a expectativa da mídia em relação à divulgação da marca Rio de Janeiro para o país e para o mundo.

As categorias Saúde (3\%), Transparência Pública (3\%), Reassentamento de Famílias (3\%), e Saneamento (3\%) vêm a seguir no número de notícias veiculadas. Há de se refletir sobre o percentual destas categorias, as quais se situam numa perspectiva mais substantiva, principalmente, os valores saúde e transparência pública.

Internet Banda Larga (2\%), Reconstrução da Cidade (2\%), Segurança Privada (2\%), Construção Civil (2\%) e Reciclagem do Lixo (2\%) compõem o quadro das categorias. Estas aparecem esporadicamente nas notícias estudadas.

\section{A FORÇA DA RACIONALIDADE INSTRUMENTAL}

O jornal Lance publicou um fórum de discussão, no período de 14 a 23 de outubro de 2009, abordando dez dimensões que podem vir a ser beneficiadas com a realização dos Jogos Olímpicos. Dentre os temas abordados, três foram considerados de importância vital para a cidade do Rio de Janeiro, a saber: a educação, a segurança e o transporte.

Apesar de ter sido destacada no fórum do Lance, a segurança aparece com 7\% no total das notícias pesquisadas para este estudo. As declarações de Tarso Genro de que o governo triplicaria os recursos para a segurança dos jogos, e já em 2009 o governo federal liberaria I 3 I milhões de reais (GOVERNO, 2009), deram a impressão de que todo o investimento teria como objetivo o bom andamento das competições e não um legado que ficaria para a cidade. $\mathrm{O} \mathrm{COI}$ colocou a questão da segurança em segundo plano para o momento inicial, preocupando-se mais com o planejamento e a infraestrutura. De acordo com declarações de integrantes do grupo do COl que veio à cidade, a prioridade é criar um organismo do governo responsável pelas obras de infraestrutura e das sedes esportivas (MATTOS, 2009). 
No fórum do jornal Lance, abordou-se a previsão de serem investidos $R \$$ 3,35 bilhões até o ano de 2012, no chamado Programa Nacional de Segurança com Cidadania (Pronasci) do governo federal, com o objetivo de implantar medidas preventivas de combate ao crime. Espera-se que outros $\mathrm{R} \$ 73$ I milhões devam ser investidos em projetos de segurança voltados aos Jogos Olímpicos. Entre os legados prometidos estão a aquisição de novos veículos e a criação de uma força única e integrada de segurança com a Secretaria Nacional de Segurança Pública - Senasp. $O$ ex-secretário de segurança pública do Rio de Janeiro, Luiz Eduardo Soares, disse não existirem políticas preventivas e intersetoriais por parte do governo e que as atuais ocupações das favelas com ações sociais ainda são vitrines atraentes, mas isoladas.

O fórum ainda apontou o transporte como uma das áreas mais sensíveis para a realização dos Jogos Olímpicos. Espera-se um investimento de $\mathrm{R} \$$ 8,9 bilhões em estradas e ferrovias, além de $\mathrm{R} \$ 2$ bilhões na reforma de portos e aeroportos. Há a previsão de que em 2016, 100\% da frota de ônibus utilize combustíveis alternativos, como o diesel e o etanol. Existe, também, a previsão da criação de barreiras acústicas nos corredores de transportes através do plantio de árvores. Outros legados relacionados ao transporte referem-se à criação de três corredores de ônibus articulados, os BRT: a linha C, com 15 km, ligando o bairro da Barra da Tijuca ao bairro de Deodoro; o corredor T5, com 29 km, ligando o bairro da Barra da Tijuca ao bairro da Penha; e um corredor de 29 km entre o bairro da Barra da Tijuca e a Zona Sul da cidade.

O fórum focalizou também a educação. Discutiu-se o censo escolar do Ministério da Educação. De acordo com os dados apresentados, em 2008, dos 1.781 colégios públicos da prefeitura do Rio de Janeiro, 803 , o que equivale a $45 \%$, não têm instalação esportiva. Em relação à rede estadual, a situação é pior, das 6.570 escolas, 3.87 I (58,4\%) apresentam a mesma deficiência. Dentre as promessas com relação à educação estão o Projeto Jovens Embaixadores, onde a partir de 20 I5, os alunos das escolas do Rio de Janeiro estudarão temas como os valores olímpicos, a cultura dos países participantes dos Jogos e as regras dos esportes. Outro projeto denomina-se Projeto Paixão, na qual 200 pessoas de comunidades carentes aprenderão línguas estrangeiras, para atuarem como guias turísticos. Com relação a investimentos na educação, o governo federal pretende investir, até 2016, o montante de $R \$ 400$ milhões na melhoria da infraestrutura das escolas públicas em todo país.

Sob todos os enfoques, até mesmo no que concerne às discussões sobre a educação, o fórum do jornal Lance ratifica a hipótese da preponderância dos aspectos instrumentais sobre os aspectos substantivos. Vê-se, por exemplo, que as abordagens priorizam o montante a ser investido e não aprofunda as discussões sobre as implicações políticas, sociais, éticas, estéticas e ambientais. 


\section{A DIMENSÃO TÉCNICA E ECONÔMICA}

Dois acontecimentos marcaram a imagem do Rio de Janeiro, virando notícia internacional. No seu programa GPS, na rede americana CNN, o apresentador Fareed Zacarias fez duras críticas à capacidade técnica da cidade em realizar uma edição dos Jogos Olímpicos. Abordou o ataque a um helicóptero da polícia, numa dura ação entre policiais e bandidos e a falta de energia elétrica que gerou um blackout em quase todo o país. Para ele, a violência e as condições de infraestrutura começam a ser questionadas, não como itens de episódios relâmpagos, mas sim, de problemas enfrentados pela população que já persiste há alguns anos (OLIVEIRA, 2009).

No entanto, a revista inglesa Economist ressalta o avanço do Brasil, que passará a ser a quinta economia mundial em 20 14, ultrapassando Inglaterra e França. Com o título Brazil takes off (o Brasil decola), a revista diz que a desconfiança contra o Brasil está mal colocada (BRAZIL, 2009).

Nestes dois exemplos, reforça-se a dimensão técnica e econômica das expectativas em relação à cidade do Rio de Janeiro, ao Brasil e à própria olimpíada de 2016.

Talvez seja importante relembrarmos que em alguns casos os megaeventos esportivos passaram a ser uma excelente ferramenta carreadora de investimentos estruturais, financeiros e profissionais, trazendo dessa forma, prosperidade e oportunidades para suas cidades-sede, à exemplo da cidade de Barcelona. Entretanto, não se pode reduzir a discussão aos aspectos relacionados ao dinheiro, investimentos, infraestrutura, negócios, etc.

Para Ribeiro (2008, p. I I 5), "o legado ideal é o que consegue ser positivo em todos os aspectos: esportivo, econômico, social e ambiental". Segundo este autor, no planejamento sempre deveria estar presente a negociação entre o tangível e o intangível, quando se aborda o legado de megaeventos esportivos.

Mazo, Rolim e DaCosta (2008, p. I I 8), apoiando-se em Poynter (2006), aduzem que:

Dentro dessa variedade de legados possíveis, podemos categorizá-los em tangíveis e intangíveis. Assim pode ser considerado legado tangível toda a infraestrutura do megaevento, pois ela é suscetível a análise econômica de custo-benefício. Já o impacto cultural do megaevento, pode ser considerado legado intangível, pois seus efeitos repercutem de modos diversos: às vezes para legitimar mudanças, outras vezes para lançar uma larga sombra sobre a cidade ou área associada a um projeto falho.

Raeder e Barbosa (2009, p. 76) dizem ser urgente a adoção de uma política urbana alternativa à que está em vigência para os megaeventos esportivos. Para eles, "deve-se primar pela conformação de um legado social composto por um 
conjunto de bens tangíveis e intangíveis que contribuam na geração de melhorias urbanas e na redução das iniquidades sociais".

Nesse sentido, não observamos, no período estudado, categorias que se relacionassem ao aumento da conscientização sobre limitações físicas (os Jogos Paraolímpicos praticamente não foram citados), acessibilidade, promoção da saúde, pertencimento à cidade, inspiração para as crianças, vida saudável, inclusão social, ampliação das atividades culturais. Ou seja, o foco, de fato, foi na técnica e no econômico.

\section{CONCLUSÃO}

A perspectiva de uma racionalidade substantiva encontra-se em segundo plano nas expectativas da mídia sobre o legado dos Jogos Olímpicos e Paraolímpicos de 2016 - como de todos os megaeventos esportivos -, nos primeiros três meses após a escolha da cidade do Rio de Janeiro como sede do evento.

Ratifica-se, portanto, que a racionalidade instrumental, mais imediatista, à base de resultados ditos palpáveis, tem um poder de difusão muito maior que a racionalidade substantiva. A instrumental é mais utilitarista, mais objetiva (no sentido de quantificável), nem por isso mais importante na fixação de políticas públicas, de legados sociais, fortalecimentos institucionais e de identidades culturais. A mídia deixou à distância a discussão sobre valores, ética e estética, potencializando os aspectos técnicos, econômicos e utilitários do legado.

Há de se observar que o instrumental e o substantivo podem se complementar, como já referido, nas teorizações de Max Weber e Jürgen Habermas e efetivamente se complementam, de acordo com experiências vitoriosas de megaeventos esportivos, como em Barcelona, em Andorra e em outras localidades. No entanto, o foco hegemônico nos aspectos instrumentais demonstra a necessidade de se estabelecer um novo marco nas discussões sobre o legado dos Jogos para a cidade e desde já.

O movimento olímpico fundamenta-se em valores substantivos. Esta é uma questão de fundo e que a racionalidade instrumental não dá conta. $\bigcirc$ conceito de sustentabilidade é um dos valores éticos que mais recentemente agregou-se a outros mais tradicionais. Devem-se desenvolver condutas responsáveis e conscientes não só para a manutenção e preservação do meio ambiente, mas também para a manutenção da paz, da cooperação, da ética, do fair play, entre outros.

$\mathrm{Na}$ qualidade de megaevento, os legados ocorrem tanto no tangível quanto no intangível e assim poderiam e deveriam ser avaliados e medidos, como por exemplo, o nível de despoluição da Baía de Guanabara e das lagoas Rodrigo de Freitas, de Jacarepaguá e Marapendi. Estudos qualitativos poderiam avaliar a conscientização, 
os valores, o respeito e a responsabilidade para com os recursos sociais, culturais e ambientais, alvos constantes de progressivo trabalho, a fim de gerar subsídios para uma consciência de pertencimento, de identidades locais e vivência comunitária.

O estabelecimento de um novo marco nas discussões passa necessariamente pelas identidades que são eleitas, mas também impostas à cidade; e pela efetiva participação dos cidadãos na preservação e construção de valores substantivos, sem que a sedução dos discursos calcados no resgate da glória ou de um futuro radioso nos afaste do tempo presente e da necessária reflexão e ação.

E é no campo educacional que vamos encontrar o espaço para a discussão de valores substantivos. Não apenas na escola; mas, concomitantemente, no trabalho, na família, na rua, no cotidiano, na mídia. E são esses valores substantivos que poderão arquitetar até mesmo elementos instrumentais, mas não o oposto (RAMOS, I 98I). Todos os objetivos traçados para os Jogos Olímpicos e Paraolímpicos deveriam ter um 'para quê?', caso contrário, a dimensão instrumental não encontrará a sua finalidade, a sua razão de ser. A racionalidade instrumental não pode servir de ferramenta para o cerceamento da felicidade. Os limites históricos da razão instrumental impõem-nos essa incessante tentativa de ultrapassá-los e de superá-los. E este desejo há que ser substantivo e não instrumental.

\section{Expectations of media on the legacy of the 2016 Olympics games: instrumental and substantive rationality}

ABSTRACT: This study aims to discuss the expectations of the media on the legacy of the 2016 Olympic Games to the city of Rio de Janeiro. We consulted 360 editions of five major newspapers published in the state of Rio de Janeiro. Seventeen categories were constructed from the analysis of news in the tabloids. The approach used in the discussion takes the concepts of instrumental and substantive rationality to analyze the historical limits which instrumental reason imposes and the continued attempt to overcome them and overcome them. KEYWORDS: Olympic Games; mega events; substantive rationality; legacy.

\section{Expectativas de los medios de comunicación sobre el legado de las olimpiadas 20 16: la racionalidad instrumental y de fondo}

RESUMEN: Este estudio tiene como objetivo discutir las expectativas de los medios de comunicación en el legado de los Juegos Olímpicos de 2016 a la ciudad de Río de Janeiro. Consultamos 360 ediciones de los cinco principales periódicos publicados en el Estado de Río de Janeiro. Diecisiete categorías se construyeron a partir del análisis de las noticias en los tabloides. El enfoque utilizado en la discusión se lleva los conceptos de racionalidad instrumental y de fondo para analizar los límites históricos que impone la razón instrumental y el intento continuo de superarlos y vencerlos.

PALABRAS CLAVE: Juegos Olímpicos; mega eventos; racionalidad substantiva; legado. 


\section{REFERÊNCIAS}

ACSERALD, H. "Apresentação". In: COMPANS, R. Empreendedorismo urbano: entre o discurso e a prática. São Paulo: Ed. da UNESP, 2005. p. I I - 14.

BALLOCO, A. Rio 20 16: projeto de três corredores expressos pela cidade. Jornal do Brasil, Rio de Janeiro, 3 out. 2009. Disponível em: <http://jbonline.terra.com.br/pextra/2009/10/04/ e04 I0 | | 89.asp>. Acesso em: 04 out. 2009.

BARDIN, L. Análise de conteúdo. Lisboa: Edições 70, 1977.

BAUDRILLARD, J. O sistema dos objetos. São Paulo: Perspectiva, 2009.

BAUMAN, Z. Identidade. São Paulo: Jorge Zahar, 2005.

BOFF, L. Nova era: a civilização planetária. São Paulo: Ática, 1994.

BRAZIL takes off. The Economist, New lork, 12 nov. 2009 Disponível em: < http://www.economist.com/opinion/displaystory.cfm?story_id=|4845 | 97>. Acesso em: 12 nov. 2009.

COMPANS, R. Empreendedorismo urbano: entre o discurso e a prática. São Paulo: Ed. da UNESP, 2005.

COSTA, R. S. O. Educação física e desenvolvimento sustentável. Niterói, IEG, 2006.

FARIA JÚNIOR, A. G. Une contribuition à I'étude du comportement verbal du professeur d'education physique: proposition du systéme FaMOC d'analyse d'enseignement. Bruxeles: Université Libre de Bruxeles, 1980.

FREITAG, B. A teoria crítica: ontem e hoje. São Paulo: Brasiliense, 1994.

FREITAS, M. Evolução do conceito de desenvolvimento sustentável. Perspectiva, Florianópolis, v. 22, n. 02, p. 547-575, jul./dez. 2004.

FURTADO, C. Introdução ao desenvolvimento: enfoque histórico-estrutural. São Paulo: Paz e Terra, 2000.

GOVERNO promete triplicar verba para segurança no Rio de Janeiro. Portalms, 28 out. 2009. Disponível em: < http://www.portalms.com.br/noticias/Governo-promete-triplicarverba-para-seguranca-no-Rio-de-Janeiro/Brasil/Geral/959564632.html>. Acesso em: 09 nov. 2009.

GREENBURG, Z. O. The World's Happiest Cities. Forbes, Nova lorque, 2009. Seção Lifestyle. Disponível em: <http://www.forbes.com/2009/09/02/worlds-happiest-cities-lifestyle-cities. html>. Acesso em: 09 nov. 2009.

HABERMAS, J. La technique et la science comme idéologie. Paris: Gallimard, 1973. 
LANDORF, H.; DOSCHER, S.; ROCCO, T. Education for sustainable development: towards a definition. Theory and Research in Education, Thousand Oaks, v. 6, n. 2, p. 22I-236, jul. 2008.

LIMA, G. C. O discurso da sutentabilidade e suas implicações para a educação. Ambiente e Sociedade, Campinas, v. 6, n. 2, p. 99-1 19, jul./dez. 2003.

LIMA, G. F. C. Educação ambiental crítica: do socioambientalismo as sociedades sustentáveis. Educação e Pesquisa, São Paulo, n. I, p. I 45-163, jan./abr., 2009.

MAGALHÃES, L. E. Rio 2016: cidade pode ganhar quase $\mathrm{R} \$ 90$ bilhões em investimentos com olimpíadas. O GLOBO, Rio de Janeiro, I out. 2009. Disponível em: <http://oglobo. globo.com/rio/rio20 I 6/mat/2009/l 0/0 I/rio-20 I6-cidade-pode-ganhar-quase-90-bilhoesem-investimentos-com-olimpiadas-767862407.asp >. Acesso em: 10 out. 2009

MARX, K. O capital. Rio de Janeiro: Civilização Brasileira, 1959.

MATTOS, R. Segurança fica de lado na visita do COI ao Rio de Janeiro. Folha, São Paulo, 30 out. 2009. Disponível em: <http://wwwl.folha.uol.com.br/folha/esporte/ult92u645290. shtml>. Acesso em: 09 nov. 2009.

MAZO, J. Z.; ROLIM, L. H.; DACOSTA, L. P. Em busca de uma definição de legado na perspectiva de megaeventos olímpicos. In: DACOSTA, L. P. et al. Legado de megaeventos esportivos. Brasília: Ministério do Esporte, 2008. p. I17-119

MURAD, M. A violência e o futebol: dos estudos clássicos aos dias de hoje. Rio de Janeiro: Ed. da FGV, 2007.

OLIVEIRA, E. Zakaria duvida da capacidade do RJ de sediar as Olimpíadas. O GLOBO, Rio de Janeiro, 16 nov. 2009. Disponível em: <http://oglobo.globo.com/blogs/brasilcomz/ posts/2009/I I//6/zakaria-duvida-da-capacidade-do-rj-de-sediar-as-olimpiadas-24 I 552. asp >. Acesso em: 16 nov. 2009.

POYNTER, G. From Beijing to bow bells: measuring the olympics effect. London: East Research Institute, 2006.

RAEDER, S.; BARBOSA, J. L. Jogos e cidades: ordenamento territorial urbano em grandes eventos esportivos. Brasília: Ministério do Esporte, 2009.

RAMOS, G. A nova ciência das organizações: uma reconceituação da riqueza das nações. Rio de Janeiro: FGV, 1981.

RECURSOS para a segurança. O Fluminense: on line, Niterói, 28 out. 2009. Disponível em: $<$ http://www.ofluminense.com.br/noticias/244604.asp?pStrLink=2,5,0,244604\&IndSeguro $=0>$. Acesso em: 28 out. 2009. 
RIBEIRO, E. Copa e Olimpíadas como chance de negócios. O GLOBO, Rio de Janeiro, 13 nov. 2009. Disponível em: <http://oglobo.globo.com/economia/seubolso/mat/2009/I I/I3/ copa-olimpiadas-como-chance-de-negocios-9|4738775.asp>. Acesso em: I 3 nov. 2009.

RIBEIRO, F. T. Legado de megaeventos esportivos sustentáveis: a importância das instalações esportivas. In: DACOSTA, L. P. et al. Legado de megaeventos esportivos. Brasília: Ministério do Esporte e Turismo, 2008. p. 107- I 16

SERVA, M. O fenômeno das organizações substantivas. Revista de Administração de Empresas, São Paulo, v. 33, n. 2, p. 36-43, mar./abr. 1993.

SILVA, C. A.; DEVIDE, F. P. Linguagem discriminatória e etnométodos de exclusão nas aulas de educação física escolar. Revista Brasileira de Ciências do Esporte, Campinas, v. 30, n. 2, p. |81-197, jan. 2009.

UNESCO. Década das nações unidas da educação para o desenvolvimento sustentável 200520 /4: documento final plano internacional de implementação. Brasília: UNESCO, 2005.

VALA, J. Análise de conteúdo. In: SILVA, A. S.; PINTO, J. M. Metodologia das ciências sociais. Porto: Afrontamento, 1986. p. I01-128.

WEBER, M. Economia e sociedade. São Paulo: Abril Cultural, 1978.

A ética protestante e o espírito do capitalismo. São Paulo: Martin Claret, 200 I.

Recebido: 13 abr. 2010 Aprovado: 03 nov. 2010

Endereço para correspondência: Carlos Alberto Figueiredo da Silva Rua Marechal Deodoro 263, Centro Niterói, RJ, Brasil CEP: 24030-060 